\title{
THE HAND STRUCTURE OF CARNOTAURUS SASTREI (THEROPODA, ABELISAURIDAE): IMPLICATIONS FOR HAND DIVERSITY AND EVOLUTION IN ABELISAURIDS
}

\author{
by JAVIER RUIZ ${ }^{1}$, ANGÉLICA TORICES ${ }^{2}$, HUMBERTO SERRANO ${ }^{2}$ and \\ VALLE LÓPEZ ${ }^{3}$ \\ ${ }^{1}$ Departamento de Geodinámica, Facultad de Ciencias Geológicas, Universidad Complutense de Madrid, 28040 Madrid, Spain; e-mail: jaruiz@geo.ucm.es \\ ${ }^{2}$ Departamento de Paleontología, Universidad Complutense de Madrid, 28040 Madrid, Spain \\ ${ }^{3}$ Instituto de Geología Económica, CSIC-Universidad Complutense de Madrid, 28040 Madrid, Spain
}

\begin{abstract}
Carnotaurus sastrei is an abelisaurid dinosaur from the Late Cretaceous of Argentina that has very reduced, but robust, forelimbs and derived hands with four digits, including a large, conical-shaped metacarpal IV lacking an articulation for a phalanx. The analysis presented in this work highlights a series of additional autapomorphies of C. sastrei. For example, the proximal phalanges are longer than the metacarpals in digits II and III, and digit III
\end{abstract}

includes only one phalanx besides the ungual. The hand of Carnotaurus shares several features with those of Aucasaurus and Majungasaurus, but the hands of the latter genera also display autapomorphies, indicating that the diversity in abelisaurid hand structure is similar to the diversity of cranial protuberances of these dinosaurs.

Key words: Dinosauria, Theropoda, abelisaurs, Carnotaurus.
CARNOTAURUS SASTREI, known from a fairly complete and articulated skeleton from the Late Cretaceous of the Argentinean Patagonia, was the first abelisaurid specimen discovered that preserved a nearly complete forelimb (see Bonaparte et al. 1990). The abelisaurids are theropod dinosaurs typical of Gondwana characterized by a short, high skull, textured maxillae, frequent presence of frontal bulking or protuberances of diverse morphologies, and highly reduced forelimbs (Sampson et al. 1998; Coria et al. 2002, Sereno et al. 2004; Carrano and Sampson 2008; Novas 2009). Abelisaurids are included in the clade Ceratosauria (Bonaparte 1991); we follow recent works that exclude coelophysoids from Ceratosauria, which is therefore considered to be the sister group of Tetanurae (for a review see Carrano and Sampson 2008).

Carnotaurus has very reduced forelimbs that display a highly derived morphology. The radius and ulna are very robust and are roughly one-fourth the length of the humerus. The hand has four digits, with the elongate and conical-shaped metacarpal IV being the largest bone in the hand (Bonaparte et al. 1990). The hands of Carnotaurus sastrei were recovered partly articulated, but several bones are lost or displaced. Presumably based on their study of the right hand of the only available specimen of
Carnotaurus, Bonaparte et al. (1990) proposed that the hand is characterized by short metacarpals (except metacarpal IV) and first phalanges, similarly to Ceratosaurus nasicornis, a ceratosaur from the Late Jurassic Morrison Formation of the United States. Bonaparte et al. (1990) interpreted several small bones found on the manus or forearm bones as carpals.

The discovery of Aucasaurus garridoi (Coria et al. 2002), from the Campanian of Patagonia, provided a second example of an abelisaurid forelimb with better preserved articulation than that of Carnotaurus, and Burch and Carrano (2008) recently gave a preliminary report of the recovery of a nearly complete forelimb of the Malagasy abelisaurid Majungasaurus crenatissimus. The hand of Aucasaurus also has four digits, but the largest bone is metacarpal I, and metacarpal IV, although conical in shape and apparently lacking an articulation for a phalanx, is comparable in size to metacarpals II and III. The metacarpals of Aucasaurus articulate directly with the forearm bones, and for this reason, Coria et al. (2002) suggested that the small bones of Carnotaurus interpreted as carpals by Bonaparte et al. (1990) could be phalanges. In this context, it is important to note that the hands of Ceratosaurus and Majungasaurus lack ossified carpals 
(Gilm•re 1920; Burch and Carran• 2008), and this is als• the case for the Chinese very basal ceratesaur Limusaurus inextricabilis (Xu et al. 2009).

In this werk, we examine the hand structure of Carnotaurus sastrei, taking int account the bønes preserved in

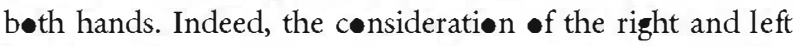
hands t•gether $\bullet$ ffers an image sharply different fr $\bullet$ that previøusly $\bullet$ btained frøm the study of the right hand

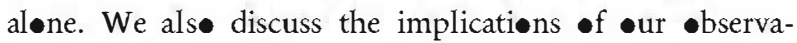
tiøns $\bullet$ f relimb diversity and evelution in abelisaurid therøpeds.

Institutional abbreviations. MACN-CH, Muse• Argentine de Ciencias Naturales 'Bernardin• Rivadavia' - C^lección Chubut, Buenes Aires, Argentina.

\section{MATERIAL}

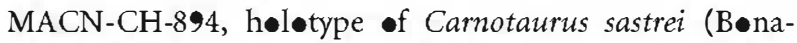
parte, 1985), was collected frøm the Late Cretaceøus (Campanian-Maastrichtian) La Cølınia førmatiøn (Lamanna et al. 2002), Chubut Prevince, Central Patagønia, Argentina. The specimen preserves nearly complete fore-

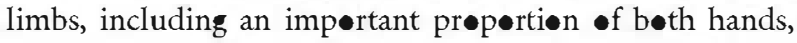
which are partly articulated, partially embedded in matrix and physically joined the respective forearms (PI. 1). Many of the preserved bønes, particularly these

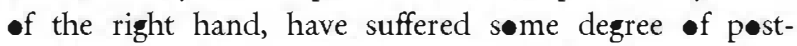

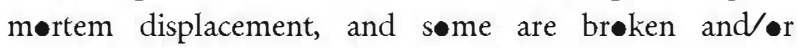
incomplete.

\section{DESCRIPTION AND COMPARISON}

The hand of Carnotaurus has four metacarpals. Metacarpal IV is the largest bone in the hand of Carnotaurus. It is well preserved in the right hand, whereas it is breken int two fragments in the left hand and its distal end is lest (Pl. 1, figs 1-2, 4). This bene is enlarged and has a conical and relatively acute distal end with out an articular facet for a phalanx. The preximal part of this bøne is rounded and includes a concave surface for the articulation with the ulna $\bullet$ its palmar side; in fact, the left metacarpal IV is preserved articulated to the ulna (PI. 1,

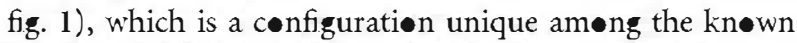
ther $\bullet$ ds that retain a fourth metacarpal. Indeed, in cøntrast to the condition in Carnotaurus, metacarpal IV is shørt and very thin, with an articulation før a small phalanx, in ceeløphysids, Ceratosaurus (e.g. Gilmere 1920; Tykeski and Røwe 2004) and Limusaurus (Xu et al. 2009). In Aucasaurus, metacarpal IV is conical and with-

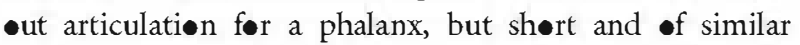
size to the metacarpals II and III (C•ria et al. 2002). S•, although the metacarpal IV of Carnotaurus presents a

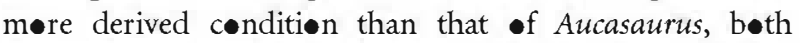
genera share a conical metacarpal IV that is of similar width to metacarpals II and III.

Metacarpals I, II and III are røbust, relatively sh॰rt and generally resemble $\bullet$ ne anther (PI. 1, figs 1-4). These

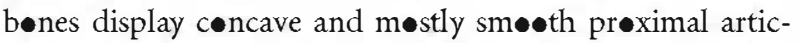
ulation surfaces, suggesting that they should articulate directly with the forearm. In fact, metacarpals II and III are preserved in the left hand in connection with the radius and ulna, respectively, and the preximal end of metacarpal II is ders laterally expanded t• previde an ample surface of articulation with the radius (Pl. 1, figs 1-2). Metacarpals directly articulated with the forearm are als exhibited by Aucasaurus (C•ria et al. 2002), and -ssified carpals are n七t present in Ceratosaurus, Limusaurus and Majungasaurus.

The length of metacarpal III •f Carnotaurus is roughly 80 per cent of that of the metacarpal II. By contrast, in

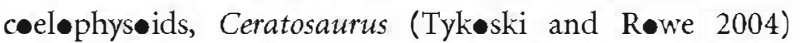
and basal Tetanurae (H•ltz et al. 2004), metacarpal III is similar in length to metacarpal II. Thus, with respect to this feature, Carnotaurus is mere derived. Metacarpal I of Carnotaurus has a similar length to metacarpal III, whereas metacarpal I is røughly as løng as half $\bullet$ metacarpal II in herrerasaurs (see Langer 2004; Nevas 2009),

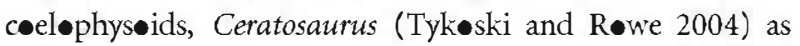
well as in the majerity of Tetanurae (H•ltz et al. 2004),

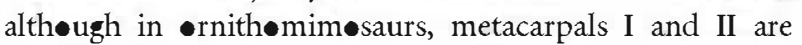
usually of similar length (e.g. Makøvicky et al. 2004).

Metacarpal I -f Carnotaurus has a cœnservative appearance, with a distal articulation for a phalanx (Pl. 1, fig.

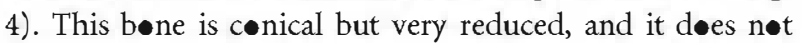
carry phalanges, in Limusaurus (Xu et al. 2009). The

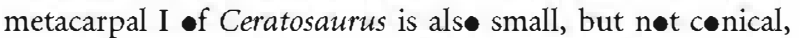
showing a greeve in its distal end, indicating the presence -f at least $\bullet$ ne phalanx in digit I. In cœntrast, metacarpal I is the løngest bøne of the hand $\bullet$ Aucasaurus, and it has a conical appearance resembling that of metacarpal IV, albeit n七ne is as derived as the metacarpal IV $\bullet$ Carnotaurus; alsø, the metacarpal I of Aucasaurus apparently did n七t bear phalanges (C•ria et al. 2002).

\section{EXPLANATION OF PLATE 1}

Figs 1-4. Hands of MACN-CH-894. 1, Right hand, dørsal view. 2, Right hand, palmar view. 3. Left hand, dørsal. 4, Left hand, palmar view. 
PLATE 1
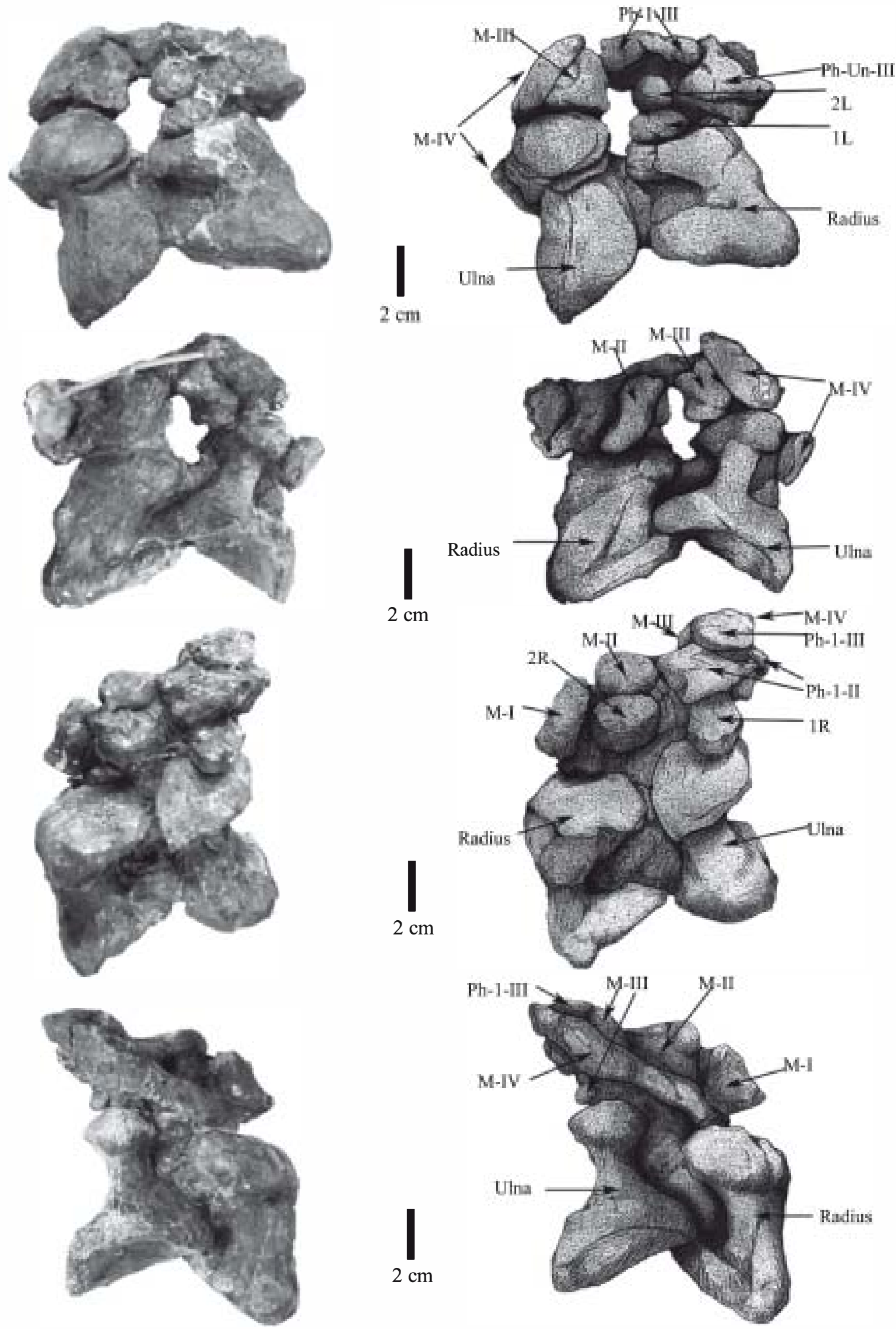
On the right hand, only a $c .1 \mathrm{~cm}$ fragment of the proximal part of phalanx 1-III is preserved (Pl. 1, fig. 3); this fragment is articulated with the metacarpal III. On the left hand, phalanx 1-III is longitudinally broken, its palmar part is lost, and a fracture separates the proximal part of the bone (which remains articulated with metacarpal III) from the distal part, which is longer but with a lesser preserved transversal section (Pl. 1, fig. 1); the distal fragment has been displaced and slightly rotated with respect to the proximal one. Because of this, the total length of this phalanx is difficult to measure exactly (we estimate it to be $40 \mathrm{~mm}$ ), although it is clearly larger than metacarpal III, a condition unique among the known theropods.

On the left hand, there is a bony piece articulated with the distal end of phalanx 1-III, which we tentatively interpret as the ungual phalanx of digit III (Pl. 1, fig. 1). This element has a roughly textured surface, an approximately conical shape and a somewhat acute end, although it is not clear whether it was sharp. Thus, digit III of Carnotaurus had only one phalanx besides the ungual.

On the right hand, a large portion of a phalanx is preserved in contact with the lateral side of metacarpal II, although its major axis is oriented perpendicular to the metacarpal (Pl. 1, fig. 3). This phalanx was interpreted by Bonaparte et al. (1990) as the phalanx 1-II. This interpretation is accepted here because metacarpal II is located between this phalanx and metacarpal I. This putative phalanx 1-II of the right hand is fractured and includes a small fragment that has been moved slightly distal to the larger fragment. Bonaparte et al. (1990) suggested that the first phalanx of digit II is relatively short, and they interpreted the minor fragment as a portion of the proximal part of a second phalanx of digit II. However, the more distal portion of the larger fragment is clearly fractured and without indications of an articulation, which supports our interpretation. The total length (around $39 \mathrm{~mm}$ ) of the preserved portion of this phalanx is difficult to estimate precisely (because of the displacement of the minor fragment), but it is comparable to the length of phalanx 1-III preserved in the left hand. Similar to the condition exhibited by digit III, phalanx $1-$ II is longer than metacarpal II, which is also unique among the theropods.

Two small bones have been recovered in each of the two hands of MACN-CH 894, although it is not clear that they represent the same elements (Pl. 1, fig. 1, 3). Bonaparte et al. (1990) interpreted these small bones as carpals, which were tentatively placed by these authors between the metacarpals II and III and the forearms. In contrast, Coria et al. (2002) suggested that these bones were probably phalanges, on the basis of the structure observed in Aucasaurus, in which carpals were not recovered and the metacarpals were directly articulated on the forearm.
All of these four small bones are preserved on the dorsal side of the hand (which may or may not be indicative of their original position), have a subcylindrical shape and are short, with a wide transverse section (Pl. 1, figs 1, 3 ). We have denoted these bones with a number and the initial of the hand side, but this terminology does not have implications for bone interpretation. On the right hand, one of these elements (1R) is placed on the ulna, whereas the other $(2 \mathrm{R})$ is on the metacarpal II, in equal distance from the ulna and from the radius ( $\mathrm{Pl}$. 1, fig. 3). In the left hand, a small bone $(1 \mathrm{~L})$ is preserved on the radius, and another (2L) lies between $1 \mathrm{~L}$ and phalanx 1III (Pl. 1, fig. 1). These bones resemble, to a certain degree, the comparatively short and featureless phalanges II-2, III-1 and III-2 of Limusaurus, which would support their interpretation as phalanges of digit I and/or II. However, preserved phalanges of the closer Carnotaurusrelatives Ceratosaurus and Aucasaurus are not as featureless as those of Limusaurus or the small bones of Carnotaurus.

An alternative interpretation, similar to that proposed by Bonaparte et al. (1990) although not exactly equivalent, would be that these bones are ossified carpals located on the dorsal side of the hand, because the metacarpals are directly articulated with the radius or the ulna. The interpretation of these bones as ossified carpals would be supported by the disposition of all the small bones on the dorsal side of the hand, by the position of $1 \mathrm{R}$ and $1 \mathrm{~L}$ near the ulna and radius, respectively, and by our observation that the only two unambiguous phalanges are relatively long. Based on these uncertainties, the correct interpretation of those small bones preserved on both hands of

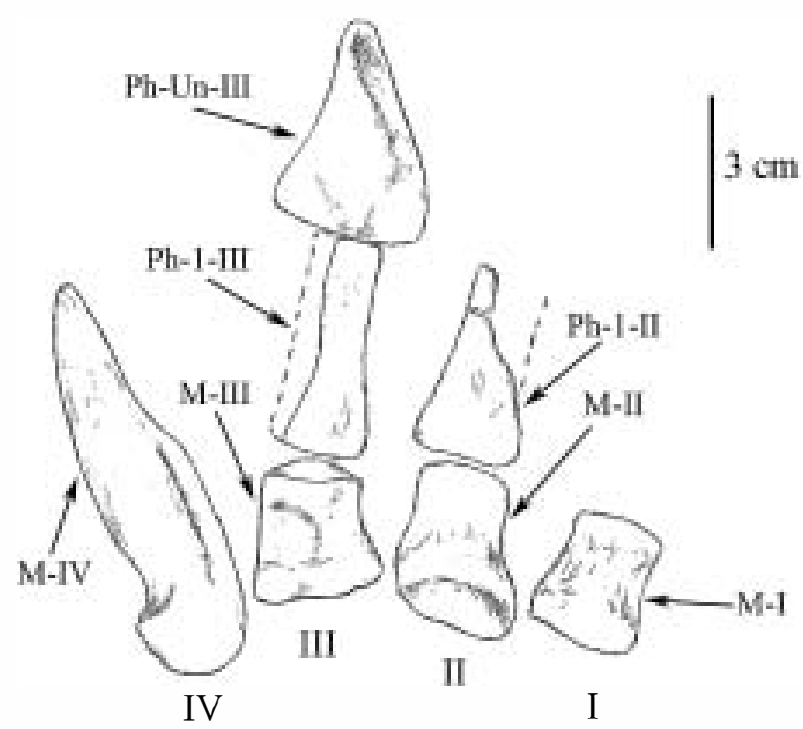

TEXT-FIG. 1. Reconstruction of the left hand (dorsal view) of Carnotaurus sastrei, based on the identified bones in both hands of MACN-CH-894 (see text for details). 
MACN-CH 894 is therefore an open question, but if they are ossified carpals, their emplacement would be extremely unusual.

The examination of the left hand of MACN-CH 894, along with a re-evaluation of the right hand, gives a new interpretation of the structure of the hand of Carnotaurus with respect to the preliminary reconstruction of Bonaparte et al. (1990, fig. 29). Indeed, metacarpals are directly articulated with the forearms, and the first phalanges in digits II and III are larger than the respective metacarpals.

\section{DISCUSSION AND CONCLUSIONS}

The structure of the hand of Carnotaurus is very peculiar, characterized by a series of features unique among the theropods (Text-fig. 1). The most obvious feature (Bona- parte et al. 1990) is the lengthened metacarpal IV, which is the largest element in the hand, with a length more than two times that of metacarpal II and which ends in a conical and relatively acute distal extremity without an articulation for a phalanx. Also, the first phalanges of digits II and III are longer than the metacarpals with which they articulate, and digit III presents only one phalanx besides the ungual. Ossified carpals are either absent or placed on the dorsal side of the hand.

Aucasaurus shares with Carnotaurus metacarpals directly articulated with the forearm, and a conical metacarpal IV without an articulated phalanx and a similar width to those of metacarpals II and III. However, the largest element in the hand of Aucasaurus is the metacarpal I, whose shape is also conical. Otherwise, the highly derived hand of Carnotaurus has a metacarpal I with a conservative appearance, similar to the metacarpals II and
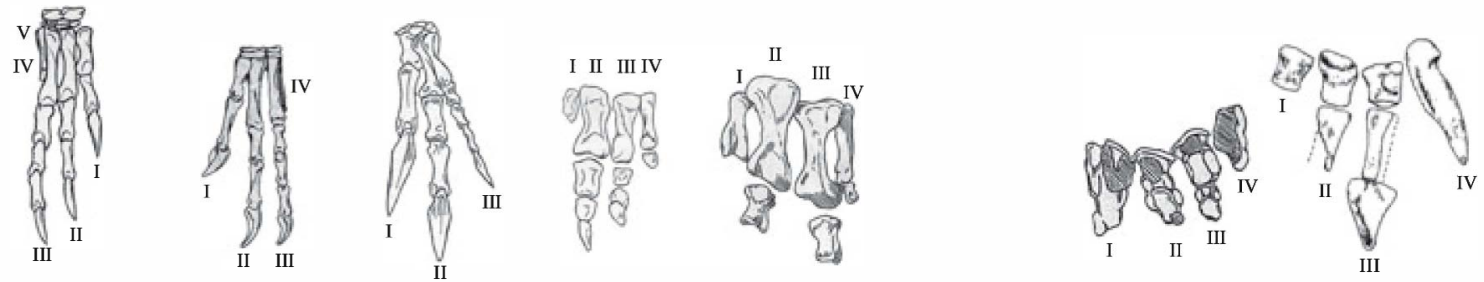

Herrerasaurus Coelophysis Allosaurus Limusaurus Ceratosaurus Majungasaurus Aucasaurus Carnotaurus

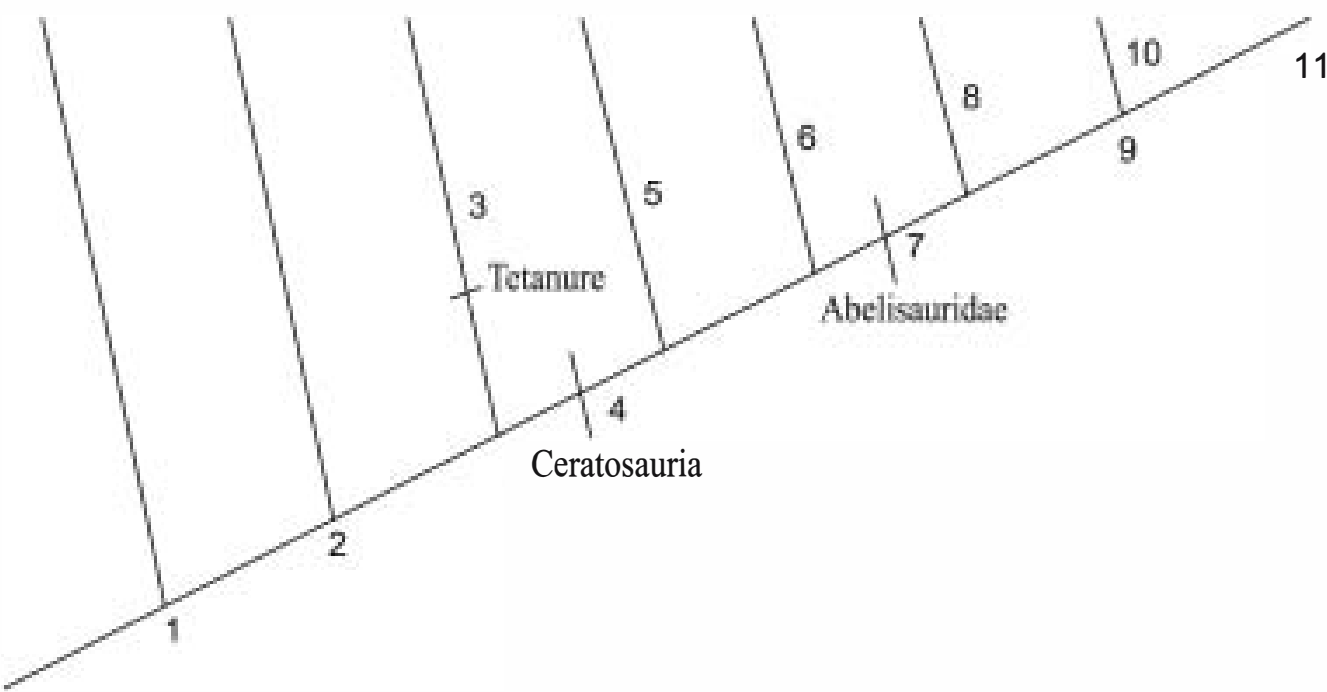

TEXT-FIG. 2. Simplified phylogeny including the left-hand anatomy of the most representative genera discussed in the text: Herrerasaurus (based on Sereno 1994), Coelophysis (based on Colbert 1989), Allosaurus (based on Norman, 1985), Limusaurus (based on Xu et al. 2009), Ceratosaurus (modified from Gilmore 1920), Aucasaurus (modified from the right hand in Coria et al. 2002) and Carnotaurus (this work). Currently, there are not available illustrations of the hand of Majungasaurus. Hands are not a scale, but shown in a similar size to facilitate comparisons. The presented phylogeny is based on Xu et al. (2009), for taxons not included in Abelisauridae, whereas for genera included in Abelisauridae, the shown relations derive from Coria et al. (2002), Canale et al. (2009) and the present work. Characters denoted by numbers: 1, elongate hand, five digits, with digit V much reduced; 2, M-II and M-III of similar length, digit IV reduced, digit V lost; 3, digit I robust, digit III thinned, digit IV lost; 4, reduction of the forearm, no ossified carpals; 5, M-I conical and much reduced; 6, first phalanges in digits II and III proportionally small; 7, M-II and M-III shortened; 8, certain degree of fusion of bones; 9, M-IV conical and of similar width to M-II and M-III; 10, M-I large, conical and without articulation for a phalanx; 11, enlargement of M-IV, P-1-II and P-1-III. There is a general trend to lost phalanges in ceratosaurs, although it cannot be exactly traced on the phylogeny. 
III. Digits II and III •f Aucasaurus preserve $\bullet$ ne and tw small phalanges, respectively, but it is unknown whether there were claws on these digits. The recently found forelimb material of Majungasaurus has n॰t been formally described, but a preliminary repert (Burch and Carran॰ 2008) described a hand with four digits, shørt metacar-

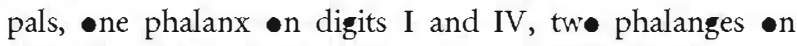
digit II and tw fused phalanges $\bullet$ digit III; the metacarpal and phalanx of digit IV are fused. The presence of a conical metacarpal IV implies a cleser relation between Carnotaurus and Aucasaurus than with Majungasaurus, in accordance with previøus werks by Coria et al. (2002) and Canale et al. (2009).

The notewrthy reduction of the abelisaurid forelimb seems to have started in basal ceratesaurs (Carran 2007;

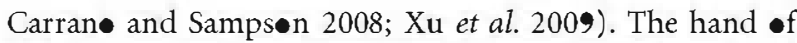
basal ceratesaurs Limusaurus and Ceratosaurus is reduced

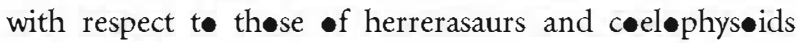
(see Text-fig. 2), with shorter metacarpals in digits II and III, and a very slender metacarpal I. Metacarpal IV •f

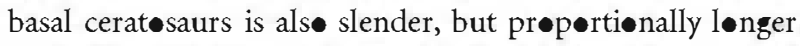
and wider (which correlates with the higher robustness the hand) than in herrerasaurs and ceeløphysids. The metacarpal II -f Ceratosaurus and Berberosaurus liassicus,

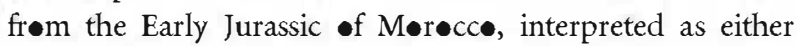
a basal abelisaureid (Allain et al. 2007) or a basal cerat saur (Carran• and Samps»n 2008), and the metacarpal III -f Austrocheirus isasii, frøm the Maastrichtian of Pata-

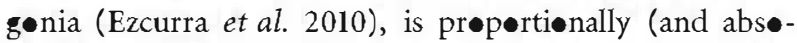
lutely) much lenger than in Carnotaurus •r Aucasaurus. S•, the large relative size of metacarpal I relative to metacarpal II in Carnotaurus and Aucasaurus is related the shertening of metacarpals II and III in abelisaurids. Basal Tetanurae such as Allosaurus (e.g. Gilmere, 1920; Textfig. 2) retain lenger metacarpals and phalanges, metacarpal III is sherter than metacarpal II, and digit IV is lest.

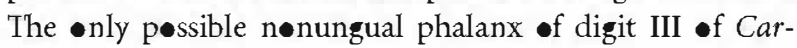
notaurus is consistent with a l-ss of manual phalanges in ceratesaurs, which als seems to be the case for Aucasaurus and Majungasaurus, althøugh the first phalanges $\bullet$ digits II and III as well as metacarpal IV have increased their length in Carnotaurus (Text-fig. 2).

The forelimbs of Carnotaurus, considered as a whøle, sh॰w an extreme reductiøn, prøpertiønally greater than

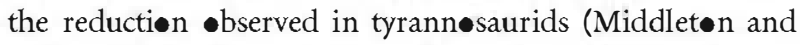
Gatesy 2000), although the radius, ulna and humerus are very robust. The forelimbs of Aucasaurus and Majungasaurus exhibit similar features, although the humerus, radius and ulna are less røust and the prepertiønal shortening of the forearms bønes is less extreme. The ulna and radius are one-fourth the length of the humerus in

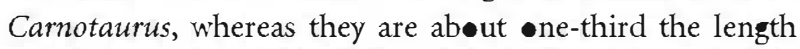
-f the humerus in Aucasaurus and Majungasaurus (Coria et al. 2002; Burch and Carran• 2008). Similarly, the humerus of Carnotaurus is relatively sherter and mere r bust than these of its tw relatives. Thus, følløwing the divergence frøm the Aucasaurus lineage, the Carnotaurus lineage shørtened the forearm and increased the røbustness of the entire forelimb.

$\mathrm{Xu}$ et al. (2009) have analysed the question of manual

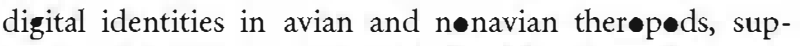
perting the shift in phalangeal identities frøm the ancestral digits I, II and III to digits II, III and IV in early Tetanurae prepesed by Wagner and Gauthier (1999). Xu et al. (2009) cite the much reduced digit I (limited to a very shert and cenical metacarpal I) and the shert phalanges in digits II and III of Limusaurus as evidence for beth digit I reduction and hand shertening before the divergence $\mathrm{f}$ Cerat sauria and Tetanurae. The metacarpal I - Limusaurus is, however, møre reduced than in latter ceratesaurs, making it unrepresentative, and therefore n॰t prøviding relevant clues for the frameshift hyp thesis.

The mørph $\bullet$ gical diversity $\bullet$ the hand $\bullet$ abelisaurids suggested by the present wørk is reminiscent of the diversity of structures found in the skull røo of these din -

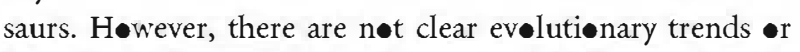

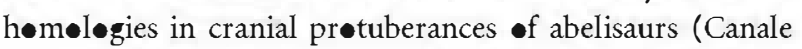

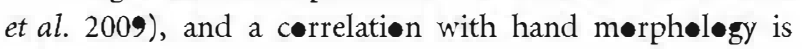
net evident.

Acknowledgements. JR thanks Alejandr• Kramarz for facilitating the access to the MACN-CH 894 specimen and for their kind

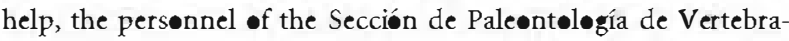
døs of the Muse Argentin• de Ciencias Naturales 'Bernardin•

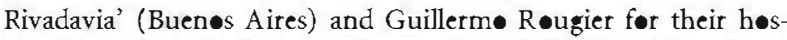
pitality, and Javier García-Guinea and María T. Alberdi for løgis-

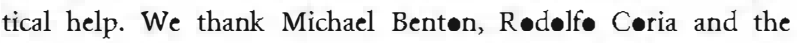
editor Kenneth Angielczyk for their reviews and suggestions, Nieves López-Martínez and Fernand• Nøvas for their comments -n this wørk, and Nita Lawsøn and Jean-Pierre Williams for language assistance.

Editor. Kenneth Angielczyk

\section{REFERENCES}

ALLAIN, R., TYK@SKI, R., A UESBI, N., JALIL, N., M-NBAR-N, M., RUSSELL, D. and TAQUET, P. 2007. An abelisaur $\bullet$ id (Dinøsauria: Ther $\bullet$ da) fr $\bullet$ the Early Juras-

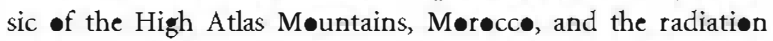
-f cerat@saurs. Journal of Vertebrate Paleontology, 27, 610-624.

B NA PARTE, J. F. 1991. The Gøndwanian ther pøilies Abelisauridae y N easauridae. Historical Biology, 5, 1-25.

N N VAS, F. E. and C@RIA, R. A. 1990. Carnotaurus sastrei Bonaparte, the horned, lightly built carnesaur from the middle Cretaceous of Patagenia. Contributions in Science, 416, $1-41$.

BUR CH, S. and CARRAN - M. 2008. Abelisaurid forelimb ev॰lution: new evidence frøm Majungasaurus crenatissimus 
(Abelisauridae: Ther $\bullet \bullet$ da) from the late Cretaceous of Madagascar. Journal of Vertebrate Paleontology, 22 (Suppl. 3), $58 \mathrm{~A}$.

CANALE, J. I., SCANFERLA, C. A., AGN LIN, F. L. and N $\bullet$ A S, F. E. 2009. New carniverøus dinøsaurs from the Late Cretaceeus of NW Patagenia and the evelution of the abelisaurid therøpds. Naturwissenschaften, 96, 409-414.

CARRAN - M. T. 2007. The appendicular skeleton of Majungasaurus crenatissimus (Ther $\bullet \bullet$ da: Abelisauridae) fr $\bullet$ the Late Cretaceous of Madagascar. Majungasaurus crenatissimus from the Late Cretaceous of Madagascar. Society of Vertebrate Paleontology Memoir, 8, 163-179.

- and SAMPS N, S. D. 2008. The phylıgeny $\bullet$ Cerat•sauria (Dinøsauria: Therøpda). Journal of Systematic Paleontol ogy, 6, 183-236.

C LBERT, E. H. 1989. The Triassic dinøsaurs Coelophysis. Museum of Northern Arizona Bulletin, 53, 1-69.

C RIA, R. A., CHIAPPE, L. M. and DINGUS, L. 2002. A new close relative of Carnotaurus sastrei Bønaparte 1985 (Therøpda: Abelisauridae) fr $\bullet$ the late Cretace us $\bullet$ Patagonia. Journal of Vertebrate Paleontology, 22, 460-465.

EZCURRA, M. D., AGN LIN, F. L. and AND N॰VAS,

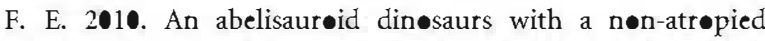
manus from the Late Cretaceous Pari Aike Førmation of søuthern Patagenia. Zootaxa, 2450, 1-25.

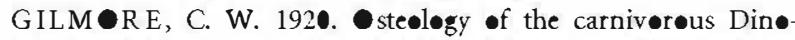
saurs in the United State National Museum, with special reference to the genera Antrodemus (Allosaurus) and Ceratosaurus. Bulletin of the United States National Museum, 110, 1-154.

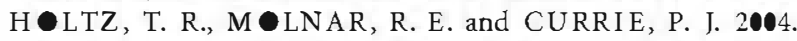
Basal Tetanurae. 71-110. In WEIS HAMPEL, D. B., D B$S-N, P$. and $S M O L S K A, H$. (eds). The Dinosauria, Sec-nd editiøn. University of Califørnia Press, Berkeley, CA, 861 pp.

LAMANNA, M. C., MARTÍNEZ, R. D. and SMITH, J. B. 2002. A new abelisaurøid therøpd frøm nørthwestern Patagenia. Journal of Vertebrate Paleontology, 22, 58-69.

LANGER, M. C. 2004. Basal Saurischia. 25-46. In WEISHAMPEL, D. B., D-BS@N, P. and SMÓLSKA, H. (eds). The Dinosauria, Second edition. University of Califørnia Press, Berkeley, CA, 861 pp.

MAK@VICKY, P. J., K BAYASHI, Y. and CURRIE, P. J. 2004. Onith mimøsauria. 137-150. In WEISHAMPEL, D. B., D-BS N, P. and SMÓLSKA, H. (eds). The inosauria, Second edition. University of Califørnia Press, Berkeley, CA, $861 \mathrm{pp}$.

MIDDLET N, K. M. and GATESY, S. M. 2000. Therøp⿺ forelimb design and evelution. Zoological Journal of the Linnean Society, 128, 149-187.

N - RMAN, D. 1985. The illustrated encyclopaedia of dinosaurs.

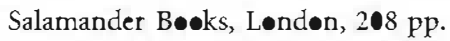

N V A S, F. E. 2009. The age of dinosaurs in South America. Indiana University Press, Bløømingten, IN, xxi $+452 \mathrm{pp}$.

SAMPS N, S. D., WITMER, L. M., F RSTER, C. A., KRAUSE, D. W., 'C NN R, P. M., D DS N, P. and RAVAVY, F. 1998. Predatery din saur remains from Madagascar: implications for the Cretaceus biogeography of Gendwana. Science, 280, 1048-1051.

SEREN O, P. C. 1994. Dinøsaurian precursørs frøm the Middle Triassic of Argentina: Marasuchus lilloensis, gen. n๑v. Journal of Vertebrate Paleontology, 14, 53-73.

WILS N, J. A. and C NRAD, J. L. 2004. New dinøsaurs link southern landmasses in the Mid-Cretaceous. Proceedings of the Royal Society of London, Series B, 271, 1325-1330.

TY K@SKI, R. S. and R WE, T. 2004. Ceratosauria. 47-70. In WEISHAMPEL, D. B., D-BS-N, P. and SMÓLSKA, H. (eds). The Dinosauria, Second edition. University of California Press, Berkeley, CA, 861 pp.

WAGNER, G. P. and GAUTHIER, J. A. 1999. 1,2,3=2,3,4: a sølution to the problem of the hømegy of the digits in the avian hand. Proceedings of the National Academy of Sciences, USA, 96, 5111-5116.

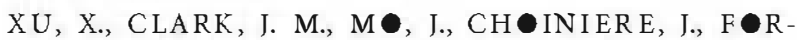
STER, C. A., ERICKS@N, G. M., H@N E, D. W. E., SULLIVAN, C., EBERTH, D. A., NESBITT, S., ZHA •, Q., HERNANDEZ, R., JIA, C., HAN, F. and GU •, Y. 2009. A Jurassic cerat $\bullet$ saurs fr $\bullet$ China helps clarify avian digital

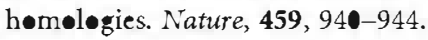

